Eastern Illinois University

The Keep

Faculty Research \& Creative Activity

Biological Sciences

January 2013

\title{
Assessing Multiple Endpoints of Atrazine Ingestion on Gravid Northern Watersnakes (Nerodia sipedon) and Their Offspring
}

Lorin A. Neuman-Lee

Eastern Illinois University

Karen F. Gaines

Eastern Illinois University, kfgaines@eiu.edu

Kyle A. Baumgartner

Eastern Illinois University

Jayme R. Voorhees

Eastern Illinois University

James M. Novak

Eastern Illinois University, jmnovak@eiu.edu

See next page for additional authors

Follow this and additional works at: http://thekeep.eiu.edu/bio_fac

Part of the Biology Commons

\section{Recommended Citation}

Neuman-Lee, Lorin A.; Gaines, Karen F.; Baumgartner, Kyle A.; Voorhees, Jayme R.; Novak, James M.; and Mullin, Stephen J., "Assessing Multiple Endpoints of Atrazine Ingestion on Gravid Northern Watersnakes (Nerodia sipedon) and Their Offspring" (2013). Faculty Research \& Creative Activity. 256.

http://thekeep.eiu.edu/bio_fac/256

This Article is brought to you for free and open access by the Biological Sciences at The Keep. It has been accepted for inclusion in Faculty Research \& Creative Activity by an authorized administrator of The Keep. For more information, please contact tabruns@eiu.edu. 
Authors

Lorin A. Neuman-Lee, Karen F. Gaines, Kyle A. Baumgartner, Jayme R. Voorhees, James M. Novak, and Stephen J. Mullin 


\title{
Assessing Multiple Endpoints of Atrazine Ingestion on Gravid Northern Watersnakes (Nerodia sipedon) and Their Offspring
}

\author{
Lorin A. Neuman-Lee, Karen F. Gaines, Kyle A. Baumgartner, Jaymie R. Voorhees, \\ James M. Novak, Stephen J. Mullin \\ Department of Biological Sciences, Eastern Illinois University, Charleston, Illinois \\ 61920, USA
}

\begin{abstract}
Ecotoxicological studies that focus on a single endpoint might not accurately and completely represent the true ecological effects of a contaminant. Exposure to atrazine, a widely used herbicide, disrupts endocrine function and sexual development in amphibians, but studies involving live-bearing reptiles are lacking. This study tracks several effects of atrazine ingestion from female Northern Watersnakes (Nerodia sipedon) to their offspring exposed in utero. Twenty-five gravid N. sipedon were fed fish dosed with one of the four levels of atrazine $(0,2,20$, or $200 \mathrm{ppb})$ twice weekly for the entirety of their gestation period. Endpoints for the mothers included blood estradiol levels measured weekly and survival more than 3 months. Endpoints for the offspring included morphometrics, clutch sex ratio, stillbirth, and asymmetry of dorsal scales and jaw length. Through these multiple endpoints, we show that atrazine ingestion can disrupt estradiol production in mothers, increase the likelihood of mortality from infection, alter clutch sex ratio, cause a higher proportion of stillborn offspring, and affect scale symmetry. We emphasize the need for additional research involving other reptile species using multiple endpoints to determine the full range of impacts of contaminant exposure.
\end{abstract}

Keywords: immune function; reptiles; reproduction; sex ratio; snakes

\section{INTRODUCTION}

Many contaminants are now being recognized as environmental endocrine disruptors, defined as "an exogenous agent that interferes with the synthesis, secretion, transport, binding, action, or elimination of natural hormones in the body that are responsible for the maintenance of homeostasis, reproduction, development, and/or behavior" (Crisp et al., 1998). Many studies have examined the sublethal effects on wildlife using a variety of parameters such as behavior, survival, thyroid function, immune competence, and reproductive physiology (Bigsby et al., 1999; Ahmed, 2000; Daston et al., 2003). These sublethal effects can be detected in an individual, its progeny, or the population as a whole (Bigsby et al., 1999; Colborn and Thayer, 2000; Crews et al., 2000). However, many of the sublethal effects of these compounds are often difficult to detect using standard toxicological assays (Fagin, 2012). The complex nature of endocrine disruptor effects along with the difficulty in detecting such effects necessitates that studies performed on these compounds should encompass multiple endpoints that span a variety of biological processes and multiple generations. 
Long-term survival of an individual fits within the framework of the "subtoxic", endocrine disrupting model, because mortality from contaminant exposure may not only be owing to the direct toxicity at high doses, but can also be linked to a suppressed immune response (Vos and Moore, 1977; Ahmed, 2000; Pruett et al., 2003). Immune suppression may be caused by a chronic elevation of corticosterone (CORT), which is an energy-mobilizing hormone that often disrupts the energetic relationships between selfmaintenance (immune function), reproduction, and responding to stressors such as exposure to contamination, captivity, and/ or handling (French et al., 2007; Dhabhar, 2009).

Quantifying the effects of endocrine disruptors on multiple endpoints of an individual's reproductive biology is necessary to begin to understand the impacts such toxicants might have on populations. Endocrine disruptors have been shown to alter many endocrine systems such as the hypothalamic-pituitary-gonad and hypothalamic-pituitary-thyroid systems (Ottinger et al., 2008). One such endpoint is the interference of normal sex steroid functions and/or rates of synthesis. Estradiol, a primary sex steroid, regulates multiple facets of gestation. Monitoring estradiol levels and survival in mothers exposed to contamination is important, but determining the effects on subsequent offspring, such as differences in size, survival, sex ratio, and symmetry will provide a clearer picture of subtoxic effects that impact the population as a whole (Storrs and Kiesecker, 2004; Willingham, 2005).

Occurrence of developmental aberrations in neonates after being exposed to contamination in utero is another important endpoint (Graham et al., 1993). A widely accepted proxy for determining whether external factors affect development is measureing the symmetry of bilateral organisms (Leary and Allendorf, 1989; Parsons, 1992). Although measured traits may not have a direct effect on the individual's fitness, abnormal external symmetry, such as limb length, scale counts, cranial traits, and wing length, can correlate with a decrease in fitness (Palmer and Strobeck, 1986; Palmer and Strobeck, 1992; Qualls and Andrews, 1999). Measuring the symmetry of the scale rows is one of the only reliable measurements in snakes (the study organism in this investigation) owing to the high amount of inherent asymmetry in the organs such as the lungs, reproductive organs, liver, and kidneys (Bergman, 1963; Maina et al., 1999; Shine et al., 2000).

Atrazine, an organic triazine compound (2-chloro-4 ethylamino-6-isopropylamino-s-triazine), has been utilized as a pre-emergent herbicide in corn, sorghum, and sugarcane fields since being registered commercially in the United States in 1959. It is dispersed in aqueous form to control broadleaf plants. Battaglin et al. (2005) found detectible levels of atrazine in $100 \%$ of the water samples analyzed from streams in the midwestern United States. Of these, $57 \%$ were $>3 \mathrm{ppb}$, which the United States Environmental Protection Agency (USEPA) sets as the maximum contaminant level for atrazine in drinking water. Little debate remains that exposure to high concentrations of atrazine disrupts endocrine function (Cooper et al., 2000; Solomon et al., 2008). However, the endocrine disrupting potential of low-level exposure has become a center of controversy among the scientific community (Hayes, 2004; Solomon et al., 2008). 
Many negative effects have been associated with atrazine exposure. For example, atrazine has been implicated in immunosuppression by making salamanders more susceptible to viruses (Forson and Storfer, 2006), decreasing antibody response in rats (Rooney et al., 2003), decreasing innate immune responses in frogs (Brodkin et al., 2007), and downregulation of genes that regulate immune function in tadpoles (Langerveld et al., 2009). Additionally, a large body of evidence shows that amphibians undergo "chemical castration" when exposed to atrazine (Langlois et al., 2009; Hayes et al., 2010, 2011; Rohr and McCoy, 2010; Hayes et al., 2011), and therefore show female sexratio biases. Although the mechanism of action is not precisely known, atrazine has been correlated with disruption in many hormonal systems, especially the endocrine systems that control reproduction (Cooper et al., 2000; Friedmann, 2002; Hayes et al., 2002).

Atrazine has been extensively studied in various contexts; however, the vast majority of studies have been conducted on amphibians and fish. Reptiles, however, are underrepresented in atrazine studies and in ecotoxicological research as a whole. They have the potential to be model study organisms for these types of studies because they (1) exhibit high site fidelity, (2) are long-lived, (3) are primarily carnivorous, and (4) have less permeable skin that amphibians and fish, and (5) have multiple routes of exposure (dermal, through egg shells, diet, and in utero; Hopkins, 2000; de Solla et al., 2007; Weir et al., 2010; de Solla and Martin, 2011). To date, the most commonly used reptiles for research involving organic contaminants are the Common Snapping Turtle (Chelydra serpentina) and the American Alligator (Alligator mississippiensis; Guillette and Gunderson, 2001; de Solla et al., 2002). Ecotoxicological research involving squamates (snakes and lizards) has remained particularly sparse although the Banded Watersnake (Nerodia fasciata) has been the subject of several studies involving exposure to heavy metals in the field (Ohlendorf et al., 1988; Hopkins et al., 1999; Murray et al., 2010), and the Western Fence Lizard (Sceloporus occidentalis) has been investigated in laboratory studies (Talent et al., 2002; Holem et al., 2008; McFarland et al., 2008).

The Northern Watersnake (Nerodia sipedon) is an important receptor species for ecotoxicological studies, given its life history, its abundance throughout much of the Midwest United States (Gibbons and Dorcas, 2004), and also because it is a live-bearing, or viviparous, reptile that typically reproduces every year. Equally important, the species is carnivorous, with the majority of its diet being fish and amphibians (Fitch, 1987; King, 1993), giving it a high potential for exposure to agricultural runoff through ingestion of both the prey item and the surrounding water. Although atrazine is persistent in the environment, there is no evidence of trophic transfer or bioaccumulation (Solomon et al., 1996). Toxicokinetic studies have shown that atrazine is taken into the body rapidly and is excreted or metabolized quickly (Gorge and Nagel, 1990; Edginton and Rouleau, 2005). However, if the concentration of the herbicide is fairly constant in the aquatic environment, these organisms will be continuously taking in and excreting atrazine and will therefore have atrazine in the body tissues.

The purpose of this study was to assess the effects of atrazine ingestion by wild-caught $\mathrm{N}$. sipedon and their offspring using multiple endpoints. The mothers were assessed 
by measuring plasma estradiol levels on a weekly basis and survival throughout the 3month gestation period. To determine the effects of atrazine ingestion on the offspring that had been exposed in utero, we compared morphometrics, sex ratio, stillbirth, and anatomical symmetry in offspring representing four different treatments.

\section{MATERIALS AND METHODOLOGY}

\section{Study Sites and Specimen Collection}

During or shortly after their emergence from hibernacula in April 2009, nine female and seven male N. sipedon were collected at Lake Charleston near Charleston, Coles, Illinois (39.467139 lat., 288.1468785 long.). Another 16 female and 5 male snakes were collected at Lake Mattoon, Cumberland, Illinois (39.33337 lat., -88.48172 long.). Although not directly connected, these lakes are within the same watershed and are connected via patchy habitat. Therefore, we are able to consider snakes from these locations as one population. Further, all statistical analysis showed no difference between these two locations $(p>0.1)$. Animals were collected in accordance with an Illinois Department of Natural Resources permit (\#NH09-0942) issued to S.J.M. Mass (+-0.1 g) and snout-vent length (SVL; +-1 mm) were recorded for each individual using standard methods. Each individual was marked uniquely using a medical cauterizer (Winne et al., 2006) and sex was verified using a cloacal probe. Males were immediately paired with females. After 1 week of being paired with a single female, the male was rotated to a new female for an additional week to increase the likelihood of insemination (Riches, 1976). Females were mated for 2-3 weeks prior to treatment. All preceding and following procedures were approved by the Eastern Illinois University Institutional Animal Care and Use Committee (IACUC) under protocol \#08-010.

Each snake was housed in a 30x30x60 cm plastic cage and provided with newspaper substrate, a water dish, a rock to aid shedding, and a plastic shelter. Each cage was exposed to a heat strip along one end, providing a thermal gradient of $24-34 \mathrm{C}$, and a 12:12 light:dark photoperiod of ultraviolet light (Ford 1995; Mullin and Mushinsky, 1997). Mothers were allowed to bask in a large aquarium with a heat lamp twice a week for $1 \mathrm{~h}$.

\section{Atrazine Preparation and Ingestion}

The atrazine (technical grade, 98.9\%, ChemService, West Chester, PA) was dissolved in $1 \mathrm{~mL}$ of $95 \%$ ethanol, and mixed with $1 \mathrm{~L}$ of diH2O. Using this as a stock solution, the three treatment groups $(2,20$, and $200 \mathrm{ppb})$ were mixed via serial dilution. The control solution was $1 \mathrm{~mL}$ of $95 \%$ ethanol and $1 \mathrm{~L}$ of diH2O. Verification samples were confirmed using a magnetic particle competitive enzyme-linked immunosorbent assay specific for atrazine (ELISA; Abraxis, Warminster, PA (Abraxis, 2008b)). The concentrations used for our study are all realistic ecological amounts in surface waters in central Illinois (Gross, 2009).

Beginning on June1, 2009, each mother began to receive one of the following randomly 
selected dietary atrazine treatments: 0 (control; $1 \mathrm{~L}$ of diH2O with $1 \mathrm{~mL}$ of $95 \%$ ethanol), 2,20 , or $200 \mathrm{ppb}$ of atrazine. Live minnows (Notropis sp.; Pana Bait, Pana, IL) were obtained weekly and received an intramuscular injection of $0.1 \mathrm{~mL}$ of atrazine solution per gram of fish so that the fish, regardless of mass, contained the same concentration of atrazine. The amount of fish with each solution was mass-corrected for each snake on a weekly basis such that each snake received the identical atrazine concentration. These concentrations are meant to represent potential environmental levels of atrazine, not necessarily within the fish. However, ingestion of fish provided an appropriate medium for dosing individuals. After injection, the fish were immediately offered to the respective snake for a period of not more than $1 \mathrm{~h}$ to avoid any degradation of atrazine. In rare cases when the fish were not consumed, the mothers were force fed by coaxing the snake to swallow the fish to ensure that each female was continuously exposed to the appropriate atrazine concentration throughout gestation. To standardize the food intake, mothers were fed $5 \%$ of their body mass twice weekly.

In mid- to late August, mothers were observed closely for signs of parturition. Stillborn offspring were measured (mass and SVL), probed for sex determination, marked uniquely with a sequence of white paint dots and frozen at -20C. Live born offspring were measured (mass and SVL) probed for sex determination, and photographed for identification by pattern.

\section{Blood and Plasma Sample Preparation}

Blood samples (approximately, $1 \mathrm{~mL}$ ) were obtained from each mother from the caudal vein on a weekly basis. The samples remained on ice for $15 \mathrm{~min}$ before being spun in a microcentrifuge for $10 \mathrm{~min}$ at $8000 \mathrm{rpm}$, which separated the plasma from the red blood cells. The plasma was removed and placed in a $1.5-\mathrm{mL}$ vial and frozen at $2208 \mathrm{C}$ until further analysis.

\section{Extraction and Detection of Estradiol}

The plasma was thawed on ice for approximately $20 \mathrm{~min}$ and then prepared for the ELISA evaluation by performing a solid-phase extraction (SPE; protocol modified from Newman et al., 2008). A known concentration of 17b-estradiol (Steraloids, Newport, RI) was extracted to determine the percent recovery.

Dilutions were necessary to obtain concentrations within the detection range of the ELISA kit (2.5-25 pg/L) and were performed according to the protocol (Abraxis, 2008a). These diluted samples were shaken for $1 \mathrm{~h}$ and then analyzed using the 17b-estradiol (E2) ELISA Kit (magnetic particle) manufactured by Abraxis LLC (Warminster, PA). This is a competitive ELISA that binds exclusively to $\mathrm{E} 2$ with uniform monoclonal antibody quality. A conjugate, 17b-estradiol-enzyme, is used to determine the concentration of E2 in the sample. The concentrations were determined all at $450 \mathrm{~nm}$, based on a standard curve. All concentrations were determined using a microplate reader.

\section{Maternal Mortality and Infection}


Throughout the study, each snake was monitored for any signs of weakness, sickness, or other indicators of a decline in health. Approximately, 3 weeks after the first dose of atrazine, some of the mothers began showing signs of infection on the scales and skin. The progression of this infection was noted until the termination of the experiment or the death of the snake. All individuals experienced at least one of the symptoms of this infection during this study. Other causes of mortality were noted. Necropsies were performed on any individual that died to determine possible cause of death. If a mother died for a reason unrelated to a scale infection (i.e., the individual had no or minor symptoms of infection and another cause was apparent), its cause of death was categorized differently from those individuals presenting symptoms characteristic of the scale/skin infection.

\section{Stillborn Offspring}

Upon birth (or removal from the deceased mother's oviduct) and measurement, each offspring was marked individually and frozen at -20C for further analysis in sealed plastic containers to prevent desiccation. All neonates, regardless of their condition (born live/stillborn/removed from oviduct), were analyzed for effects on mass, SVL, and sex ratio. Many mother snakes gave birth to fully developed but dead offspring. The proportion of live to dead offspring for each snake was recorded. Mothers that died before parturition did not have any of their offspring included in the analyses of stillborn neonates.

\section{Scale and Jaw Asymmetry}

The neonates were measured for asymmetry to assess possible aberrations in development. All offspring that had full scalation were used in the analyses of these characteristics. The left and right dorsal scales extending from the mid-dorsal scales were counted at 25,50 , and $75 \%$ of the SVL for each snake using a dissecting microscope. After all offspring were measured, the count was repeated for each individual to ensure accuracy. Additionally, clefts in ventral scales were counted for each individual because clefts in snakes are considered abnormal.

Digital radiographs of the dorsal view of each offspring were produced to analyze left and right jaw length. The distance from the anterior margin of the premaxilla to the posterior margin of the quadrate bone was recorded using ImageJ (National Institute of Health, 2010).

\section{Statistical Analyses}

Assumptions of normality and homoscedasticity were tested (PROC UNIVARIATE; SAS v9.0, SAS Institute, Cary, NC). Unless otherwise stated, no transformations were needed to meet these assumptions. To ascertain whether or not female size varied among treatment groups at the beginning of the experiment, an analysis of variance (ANOVA) was used to compare the initial masses at capture of all mothers as a function of 
treatment. An ANOVA was also used to determine if treatment affected the change between initial mass at capture and mass at the end of the treatment (at 3 months).

The concentration of estradiol was log-transformed to meet the assumption of normality prior to any analyses. As three mothers did not give birth, analyses were performed on mothers that gave birth only (control $n=5 ; 2$ ppb $n=7 ; 20$ pp $n=6 ; 200 p p b n=5$ ) as well as all adult female snakes (control $\mathrm{n}=7 ; 2 \mathrm{ppb} \mathrm{n}=7 ; 20 \mathrm{ppb} \mathrm{n}=6 ; 200 \mathrm{ppb} \mathrm{n}=6$ ) combined. Estradiol concentrations for the gravid females (mean, 155.09 +- 8.94, SE) and nongravid female snakes (mean, $140.39+-22.22$, SE) did not differ $(\mathrm{F} 1,343=0.48$, $\mathrm{p}=0.49$ ); therefore, all of the adult female snakes were pooled for all further analyses.

A general linear model (PROC GLM) was used with estradiol concentration as the dependent variable and treatment as the independent variable. A mixed model (PROC MIXED) analysis was utilized to investigate the effect of repeated measurements of the same individuals within the data where the random effect was the individual and the fixed effect was treatment. The general linear model and mixed model statistics were identical $(\mathrm{F} 3,343=1.31, \mathrm{p}=0.27)$, indicating that the variation was similar among one female's samples and samples among multiple females. For this reason, all samples were considered individual data points for the following analyses and a repeated measures test was not performed.

The two-time scales of birth week (back-calculated from when the mother gave birth) and treatment week (starting at the first week of atrazine treatment for each female and progressing until parturition) were analyzed using a linear regression (PROC REG). Because of multiple data points for each week, the deviation of linearity was also calculated by using the sum of squares of the linear regression. A series of polynomial regressions were fit up to the sixth order. The most parsimonious polynomial model was chosen using Akaike's information criterion (AIC; Akaike, 1974).

The mean estradiol concentration was calculated for each mother. A t-test was conducted comparing the control to the pooled atrazine-treated mothers. An ANOVA was not performed between each treatment owing to low sample size. Maternal mortality and cause of death were analyzed using a logistic regression with treatment as the independent variable, mass as a covariate, and treatment and mass as an interaction.

Two analyses of covariance (ANCOVA) were used to compare both SVL and mass of the neonates as a function of treatment group with the mass of the mother at capture as a covariate. A categorical model (PROC CATMOD) was used to determine the relationship between treatment and sex, treatment and neonate condition (e.g., alive vs. dead) as well as a model testing the three-way interaction. The asymmetry at each body section was assessed with an ANOVA using the difference between the left and the right side of the scale count as a function of treatment. The jaw lengths were similarly tested. 


\begin{tabular}{lccrrr} 
Model & $\begin{array}{c}\text { \# of } \\
\text { Parameters }\end{array}$ & AIC & $\Delta$ AIC & \multicolumn{1}{c}{$w_{i}$} & $\begin{array}{c}\text { Evidence } \\
\text { Ratio }\end{array}$ \\
\hline Quartic & 5 & 2397.47 & 0.00 & 0.64 & 2.00 \\
Quintic & 6 & 2398.86 & 1.39 & 0.32 & 2.72 \\
Sextic & 7 & 2400.86 & 3.39 & 0.12 & 44.26 \\
Quadratic & 3 & 2408.44 & 10.97 & 0.002 & 1.02 \\
Linear & 2 & 2408.48 & 11.01 & 0.003 & 1.67 \\
Cubic & 4 & 2409.50 & 12.03 & 0.002 & - \\
\hline
\end{tabular}

${ }^{\mathrm{a}}$ The quartic and quintic models were the best fit and indicate a pulsatile relationship between these two variables. The pulsatile pattern is shown in Figure 1.

TABLE I. AIC values determining the best fit for the nonlinear model for the concentration of estradiol in mother Northern Watersnakes (N. sipedon) and treatment week (starting at week 1 for each female and progressing until parturition)a

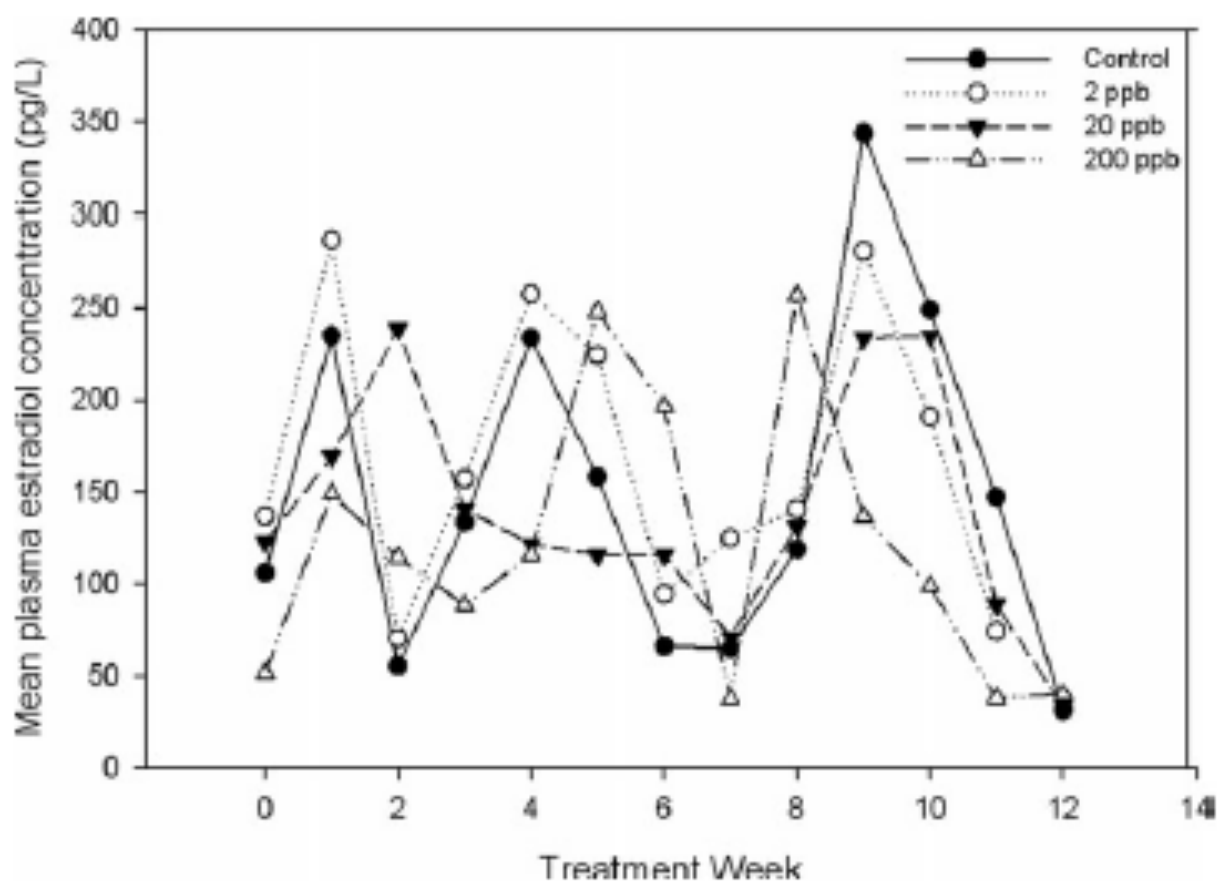

Fig. 1. Mean plasma estradiol concentration in gravid Northern Watersnakes (N. sipedon) exposed to one of the four atrazine treatments as a function of the week of treatment. Table I summarizes all statistical evidence for this pulsatile relationship between treatment week and estradiol concentrations. 


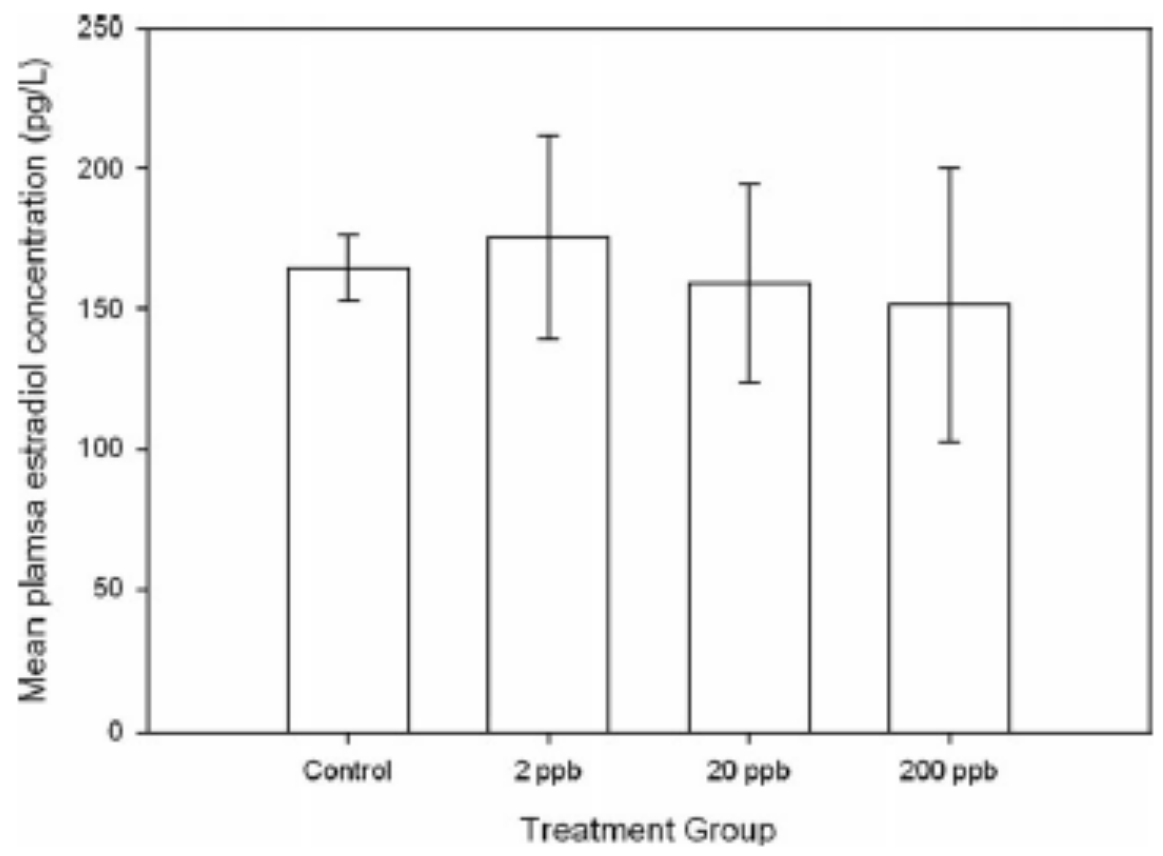

Fig. 2. Mean estradiol concentration (+-95\% confidence interval) in the plasma of gravid Northern Watersnakes (N. sipedon) during 3 months of atrazine ingestion in 2009 (control $\mathrm{n}=72 ; 2 \mathrm{ppb} \mathrm{n}=62 ; 20 \mathrm{ppb} \mathrm{n}=66 ; 200 \mathrm{ppb} \mathrm{n}=46$ ).

\begin{tabular}{llc} 
Cause of Death & Treatment & $\begin{array}{c}\text { Number } \\
\text { Affected }\end{array}$ \\
\hline Infection (see text) & Control & 1 \\
& $2 \mathrm{ppb}$ & 3 \\
& $20 \mathrm{ppb}$ & 2 \\
Oviduct perforated by & $200 \mathrm{ppb}$ & 3 \\
$\quad$ calcified embryonic plug & Control & 1 \\
Tumor & Control & 1 \\
Intestinal blockage (individual & $200 \mathrm{ppb}$ & 1 \\
$\quad$ displayed signs of advanced & & \\
infection as well) & & 1 \\
Unknown & $2 \mathrm{ppb}$ & \\
\hline
\end{tabular}

TABLE II. Causes of death described for gravid Northern Watersnakes (N. sipedon) exposed to different concentrations of atrazine during gestation in 2009, with number of individuals dying within each treatment

\section{RESULTS}

\section{Maternal Morphometrics}


Mass and SVL in females were significantly correlated $(F 5,7=8.90, p=0.01)$. However, the initial mass $(\mathrm{F} 3,22=0.69, \mathrm{p}=0.42)$ and SVL $(\mathrm{F} 3,22=0.48, \mathrm{p}=0.70)$ of the mothers did not vary among treatments.

\section{Estradiol Levels}

The SPE procedure yielded a $72 \%$ recovery rate. There was no linear pattern between the birth week and the concentration of maternal estradiol $(\mathrm{F} 1,198=0.88, \mathrm{p}=0.35)$.

Additionally, there was no deviation from the linearity for birth week (F14,198 $=1.12, p$ $=0.35$ ), indicating no relationship between treatment and estradiol for this time frame. Therefore, no further analyses were performed on birth week. The relationship between treatment week and estradiol levels was nonlinear $(\mathrm{F} 1,234=0.12, \mathrm{p}=0.73)$, with a significant deviation from linearity $(\mathrm{F} 11,234=5.25, \mathrm{p}<0.0001)$, indicating that there was a complex relationship with treatment and estradiol concentration for the treatment week time frame. Therefore, we fit these nonlinear models and the AIC and evidence ratio showed that the quartic (five parameters) model was the best fit although support for the quartic, quintic, and sextic (five to seven parameters) models was equivocal according to the AIC, DAIC, and evidence ratio measures (Table I). This nonlinear pattern is apparent from visual examination of the estradiol concentration from week to week (Fig. 1). The t-test comparing the estradiol concentrations of subjects in the control treatment to the three pooled treatment groups showed no differences among treatments $(t=2.07, p$ $=0.93$; Fig. 2).

\section{Maternal Mortality and Infection}

Mortality over the duration of the study was not affected by the concentration of atrazine received in the diet $(x 2=6.70 ; p=0.46)$. Among all treatment groups, four different causes of death were determined (Table II). The primary cause of death was an infection that spreads rapidly over an individual's scales. The initial symptoms included small to medium $(0.5-1 \mathrm{~cm})$ pustules forming between scales on the ventral side followed by deterioration of the scales, typically starting around the regions of the neck and cloaca (Fig. 3). If the infection advanced (not in all cases), symptoms became more systemic, influencing the musculature. These symptoms included (1) complete loss of scales and skin, resulting in exposure of flesh, especially around the neck; (2) weakness of muscles (as determined by palpation and body movements; and (3) poor righting response (requiring more than $30 \mathrm{~s}$ ) followed by death. Necropsies performed on individuals that died in the advanced stages of infection revealed no obvious internal trauma. When analyzing the mothers that died from infection versus the live snakes and the ones that died from other causes, larger snakes that ingested atrazine made up a higher proportion of the snakes that died from the infection $(x 2=32.22, \mathrm{p}=0.003, \mathrm{R} 2=0.63$; Fig. 4).

\section{Offspring Morphometrics}

The mass of the offspring did not differ among treatments $(F 3,9=0.97, p=0.54)$ or as a function of the mother's initial mass $(\mathrm{F} 1,9=1.00, \mathrm{p}=0.42)$. The SVL of offspring also did not differ as a function of treatment $(\mathrm{F} 3,9=2.55, \mathrm{p}=0.29)$ or mother's mass $(\mathrm{F} 1,9=$ 
$1.63, \mathrm{p}=0.31)$.

\section{Stillborn Offspring}

The concentration of atrazine in the diet that mothers received during gestation influenced the proportion of offspring that were stillborn $(\mathrm{x} 2=37.04, \mathrm{p}<0.0001 ; \mathrm{n}$ for mothers: control $=3,2 \mathrm{ppb}=5,20 \mathrm{ppb}=5,200 \mathrm{pbb}=2 ; \mathrm{n}$ for neonates: control $=58,2$ $\mathrm{ppb}=40,20 \mathrm{ppb}=35,200 \mathrm{ppb}=31$; Fig. 5). Specifically, mothers in the control group gave birth to the highest proportion of live neonates $(0.81)$, whereas the $20 \mathrm{ppb}$ group gave birth to the lowest (0.12).

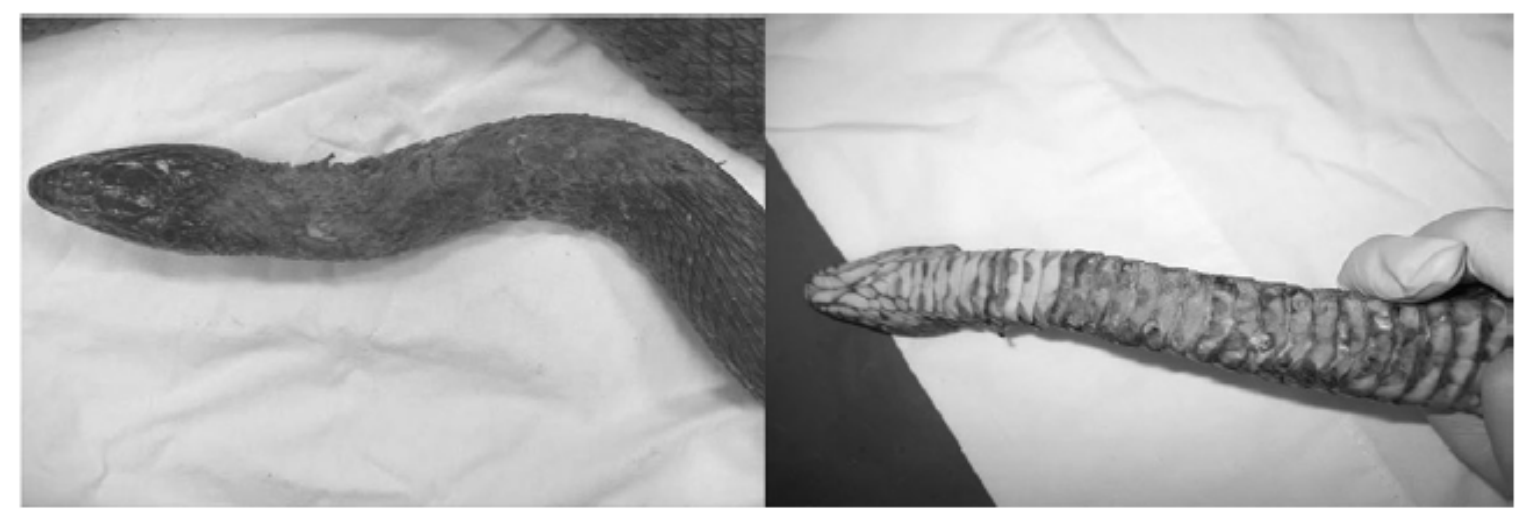

Fig. 3. Dorsal (a) and ventral (b) views of an advanced stage of scale infection of an adult female Northern Watersnake (N. sipedon) held in captivity for 2.5 months. This individual died 1 week after photograph was taken.

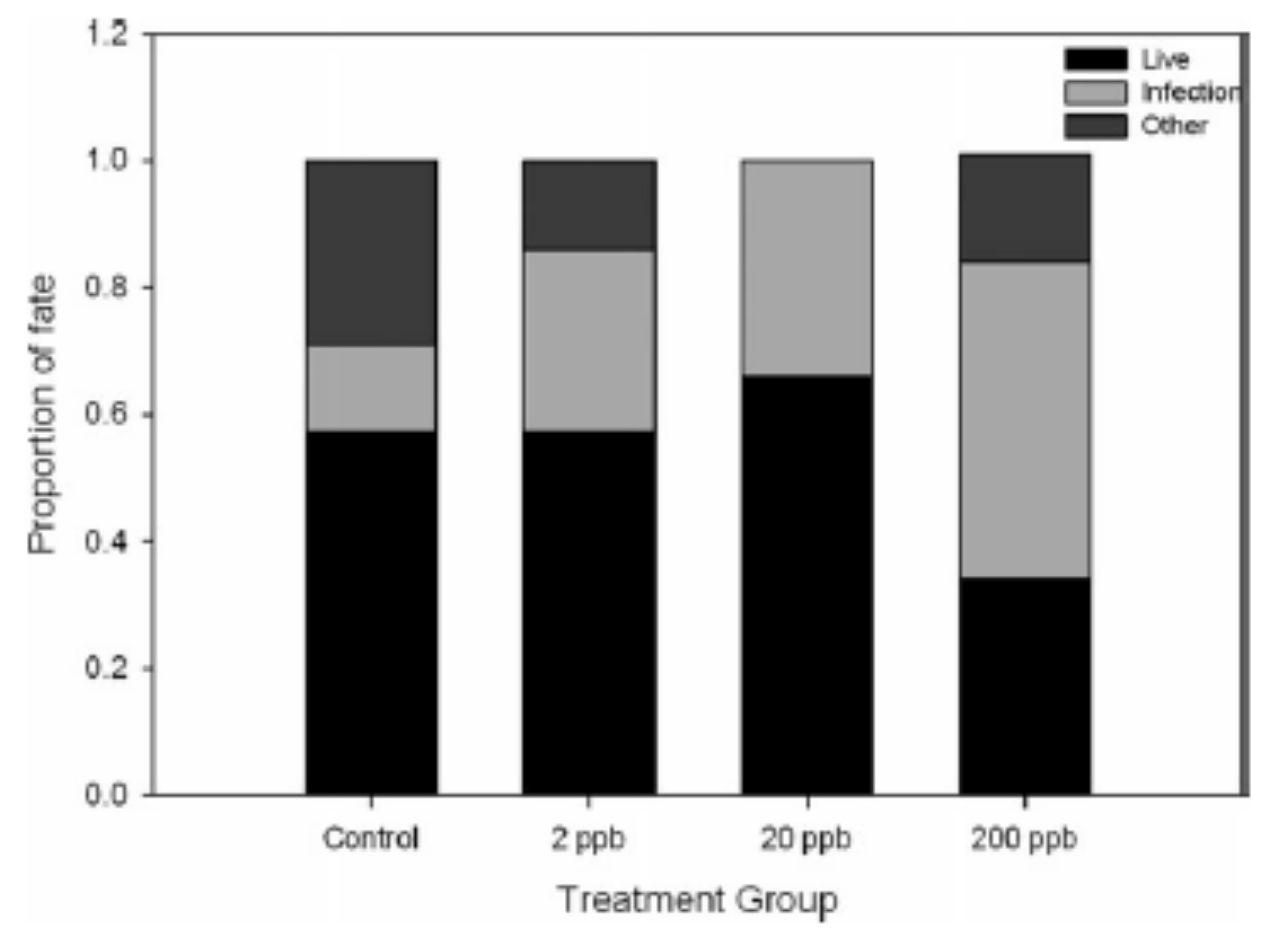

Fig. 4. Fate (expressed as a proportion) of gravid Northern Watersnakes (N. sipedon) for each of four treatment groups of atrazine exposure ( $\operatorname{control~} n=7 ; 2 p p b n=7 ; 20 p p b n=$ 
6; $200 \mathrm{ppb} \mathrm{n=6).} \mathrm{"Other'} \mathrm{indicates} \mathrm{the} \mathrm{proportion} \mathrm{of} \mathrm{the} \mathrm{individuals} \mathrm{that} \mathrm{died} \mathrm{of} \mathrm{causes}$ unrelated to any infection. "Infection" indicates the proportion of individuals that died as a result from systemic infection. "Live" indicates the proportion of individuals that survived the study.

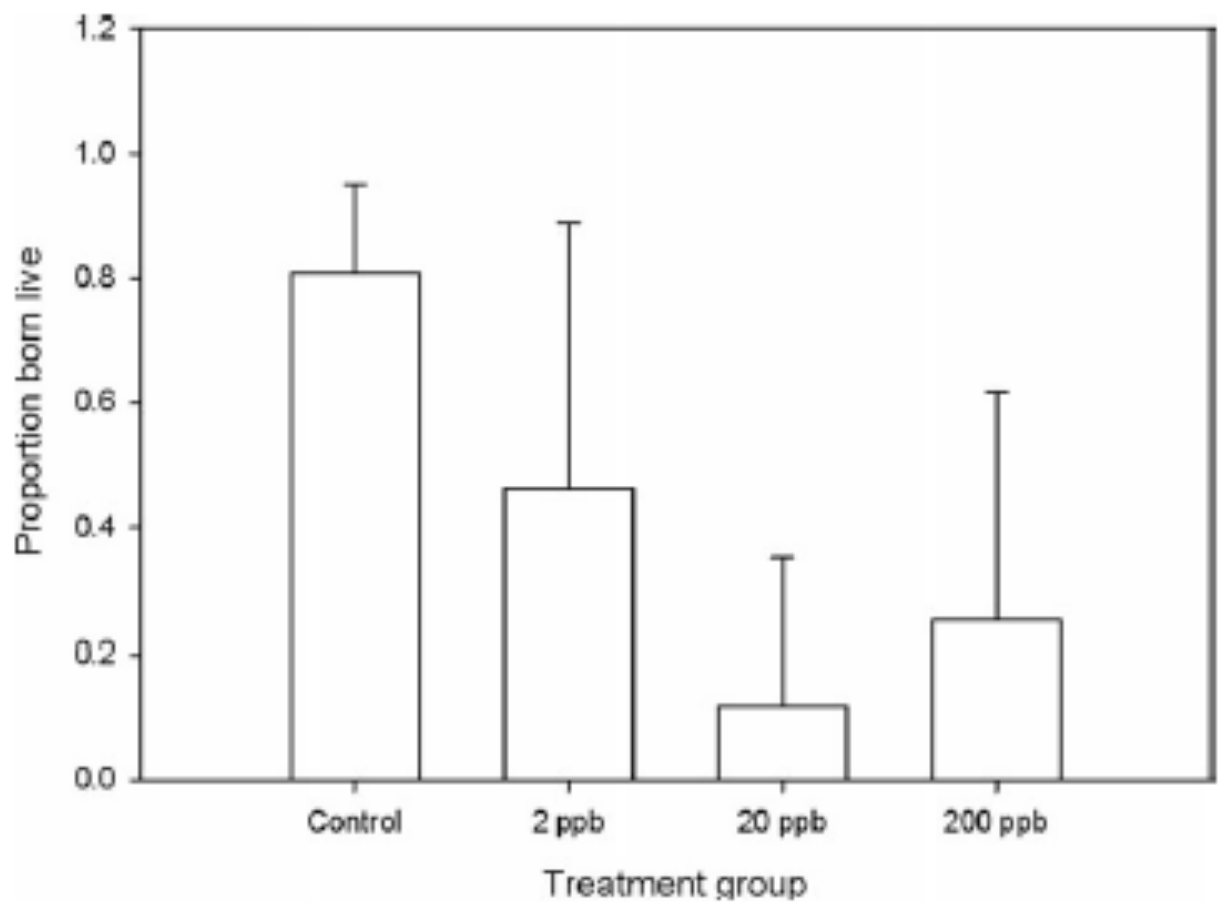

Fig. 5. Mean proportion of neonate Northern Watersnakes (N. sipedon) born live as a function of the treatment level of atrazine (control $n=58 ; 2 \mathrm{ppb} n=43 ; 20 \mathrm{ppb} n=35$; $200 \mathrm{ppb} n=31)$.

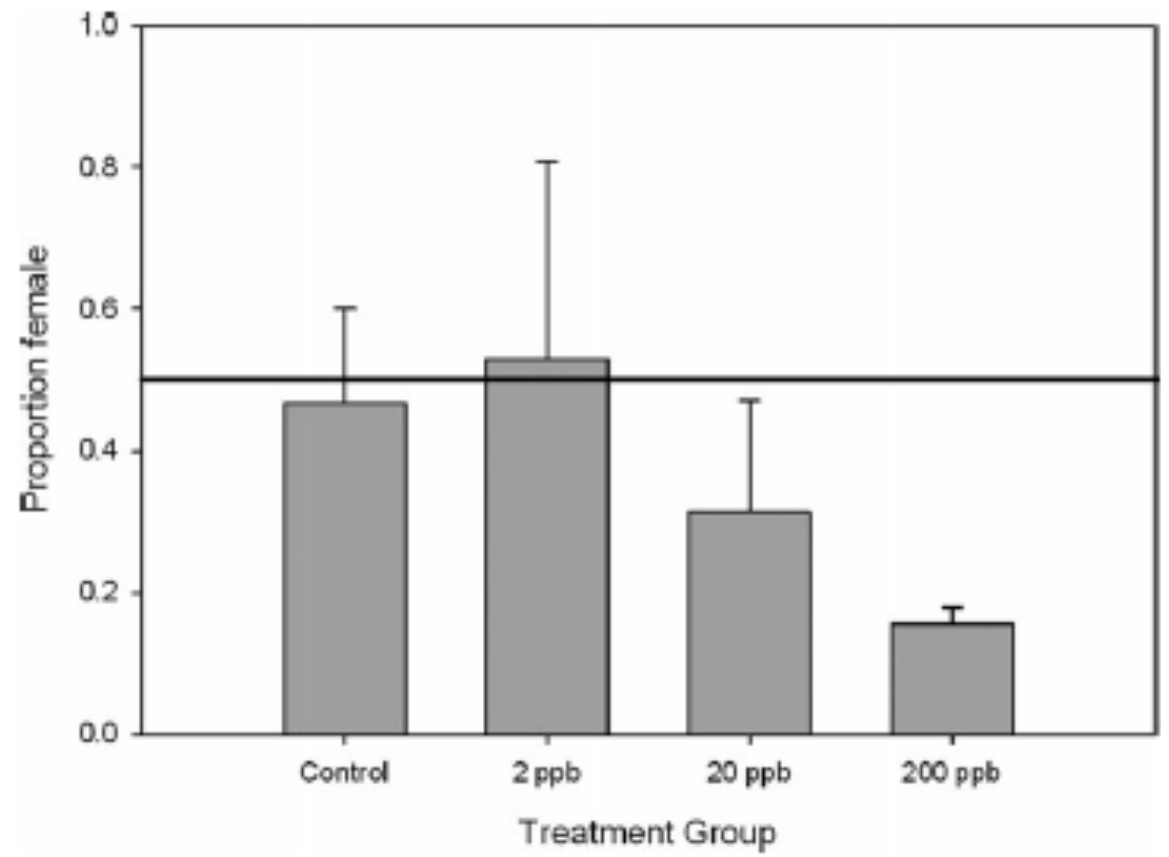


Fig. 6. Proportion of female offspring born to Northern Watersnakes (N. sipedon) in 2009 after the mothers were fed atrazine-laced fish throughout pregnancy. The black line indicates the expected $50 \%$ female offspring (control $n=58 ; 2 \mathrm{ppb} n=43 ; 20 \mathrm{ppb} \mathrm{n}=35$; $200 \mathrm{ppb} n=31$ ).

\section{Sex Ratio}

The sex ratio of the offspring varied as a function of treatment with a skew toward a male ratio, especially in the mothers exposed to the $200-p p b$ atrazine treatment $(x 2=6.54, \mathrm{p}=$ 0.09; $\mathrm{n}$ for mothers: control $=5,2 \mathrm{ppb}=4,20 \mathrm{ppb}=4,200 \mathrm{pbb}=2 ; \mathrm{n}$ for neonates: control $=78,2 \mathrm{ppb}=55,20 \mathrm{ppb}=34,200 \mathrm{ppb}=26$; Fig. 6). There was no interaction between stillborn neonates, sex, and treatment $(\mathrm{x} 2=1.10, \mathrm{p}=0.78)$.

\section{Scale and Jaw Asymmetry}

There was an effect of treatment on the scale row symmetry at the mid-body $(\mathrm{F}=11.31$; $\mathrm{p}=0.01$ ), with more asymmetries occurring in offspring born to mothers in the 20-ppb atrazine treatment $(\mathrm{p}=0.002)$. Neither treatment nor clutch affected scale row symmetry at 25 or $75 \%$ of the offspring's SVL ( $p>0.05)$. Offspring exposed to the same treatment level of atrazine exhibited similar patterns of response $(p=0.06)$. There was no relationship between ventral scute anomalies and atrazine treatment. Measurements of right and left sides of the offspring skulls were similar in all treatment groups $(\mathrm{F}=0.84, \mathrm{p}$ $=0.47)$. The mean difference between sides was $0.006 \mathrm{~mm}$ (range $=0.003-1.485 \mathrm{~mm})$.

\section{DISCUSSION AND CONCLUSIONS}

Our study provides evidence that atrazine negatively affects Northern Watersnakes. By using multiple endpoints, we were able to determine that reproductive measures and survival were negatively affected. The atrazine-treated females had a greater mortality from an infection. The mothers treated with $20 \mathrm{ppb}$ had a greatly reduced percentage of live birth and increased number of neonates showing asymmetry. Finally, there was a male-biased sex ratio in the offspring of the females treated with highest concentration of atrazine $(200 \mathrm{ppb})$. Taken all together, there are clear indications that these reptiles are likely susceptible to atrazine and potentially other environmental contaminants.

The nonlinear relationship between treatment and estradiol levels indicated that there were pulse-like estradiol concentrations throughout the treatment period regardless of treatment group. We did not detect this pulsatile pattern when back-calculating by birth week. Although we did not detect a difference in estradiol levels among treatment groups, it does appear that these females experienced pulses of estradiol throughout gestation. Other work with snakes has not shown a similar pulsatile pattern; however, time between sampling periods was much greater and may not have detected weekly fluctuations (Whittier et al., 1987; Taylor et al., 2004).

Although there are many studies that show no interaction between stress (measured by corticosterone or cortisol) and estradiol (Campbell et al., 1994; Coddington and Cree, 1995), some research indicates a relationship between the two hormones (Elsey et al., 
1991). All snakes were bled uniformly; however, we did not measure the time from initially picking up the snake to the completion of bleeding. Being exposed to a handling stressor for more than 3 min would likely elevate the corticosterone (CORT) and could potentially have interacted with the estradiol concentration within our study. CORT was likely elevated for a several reasons such as being in captivity (Morgan and Tromborg, 2007), weekly handling (Romero and Reed, 2005), and being exposed to contamination. The potential elevation from these multiple stressors could have contributed to the increased mortality in the lowest treatment group (2 ppb).

The increased mortality from infection may indicate that these individuals underwent an initiation of the emergency life-history stage (chronic elevation in CORT) owing to allostatic load (French et al., 2006, 2007; Dhabhar, 2009). This concept is based on the fact that chronic stress, if severe and prolonged, can force an organism to decrease energy allocation to functions such as reproduction and the immune response (Ross et al., 1996; Romero and Wikelski, 2001). The relationship between stress and immune function could explain the increased incidence of infection that was seen within our study. The differences seen among treatment groups reflect only differences between the dosing, because all of the snakes had at least minor signs of the infection and were handled and maintained in the exact same conditions. Exposure to contamination is considered a chronic stressor and is often correlated with elevated CORT (Hopkins et al., 1997; Lorenzen et al., 1999; Gunderson et al., 2003). Therefore, regardless of the physiological mechanism behind the response, our experiment provides evidence that atrazine has the potential to alter reproduction and immune function.

There is specific evidence to support this theory in atrazine. Atrazine has been linked to decreased long-term survival by increasing CORT levels and decreasing the number of thymus cells (Pruett et al., 2003). Few studies, however, have examined atrazine's impact on survival and/ or immunotoxicology for longer than 1 week or in a range of ecological settings (Solomon et al., 2008).

Ingested atrazine negatively affected the percentage of live births (especially at the 20$\mathrm{ppb}$ treatment level), a finding that might be an additive response to increased stress levels from the atrazine treatment, pregnancy, and the captive conditions. Robert et al. (2009) documented an increase in stillborn offspring as a result of elevated CORT plasma levels in gartersnakes (Thamnophis elegans). However, the toxicity of ingested atrazine on developing squamates has not been examined. There is additional evidence of developmental aberrations as shown by the asymmetry of the dorsal scales in the 20-ppb group, which is consistent with Campero et al. (2007), who demonstrated the effects of atrazine on developmental symmetry in insects. We also do not know if the infection directly impacted neonatal development and survival.

Within our study, there were differences among the sex ratios of the treatment groups although the sample sizes were small. The litters tended to be male biased, a finding that is supported by Matsushita et al. (2006) who found that atrazine inhibited the regression of the right gonad in young poultry, inducing male gonadal development. These results contrast work conducted on amphibians that showed a female bias (Rohr and McCoy, 
2010) and research that shows no direct impact on the sex bias in reptiles (Willingham, 2005; de Solla et al., 2006; Neuman-Lee and Janzen, 2011). Another explanation for this male-biased sex ratio may also come from elevated CORT during gestation (Pinson et al., 2011). As studies on N. sipedon populations (both captive and free living) have revealed a nonbiased sex ratio (50:50 ratio M:F; Weatherhead et al., 1998), the male-biased sex ratio observed in our study is unlikely to be a natural phenomenon, especially because our control and 2-ppb treatment were nearly $50 \%$.

Although many ecotoxicological studies focus on the effects of acute doses on mortality, this endpoint is unsatisfactory when attempting to understand the complexity of the ecological effects of a toxicant on an organism. To assess the true impacts of any contaminant, multiple endpoints must be analyzed. Although negative effects such as decreased live birth, a skewed sex ratio, and mortality were associated with atrazine ingestion, any of these single endpoints could provide only limited insight to fully elucidate of the effects of atrazine ingestion by gravid N. sipedon. When all of the endpoints are evaluated together, the negative impacts of atrazine ingestion on reproductive output of vertebrates warrant continued study. The data presented here demonstrate the complexity of ecological studies when examining the impacts of contamination on an organism. Additionally, our research on the effects of atrazine on estradiol levels, reproductive success, sex ratio, and longterm survival in Watersnakes is an important addition to the growing body of research on endocrine disruption.

The authors thank T. Bollinger, J. Hedin, N. Kiriazis, and M. Kocher for help with field collection, animal maintenance, and laboratory assistance. Special thanks to D. Douros for his invaluable assistance in analyzing the estradiol samples. The authors also thank the 2009 EIU herpetology class for assistance in collecting animals. Special thanks to J. Christman, the Albin Animal Clinic, P. Edwards, A. Newman, and C. Bobryk. The authors also thank the Mullin lab, French lab, Brodie lab, W. Hopkins, and L. Bryan for comments on earlier versions of this manuscript.

\section{REFERENCES}

Abraxis L. 2008a. 17b-Estradiol (E2) ELISA Kit (Microplate) User's Guide. ABRAXIS.

Abraxis L. 2008b. ELISA Kit for Atrazine. Abraxis, LLC.

Ahmed SA. 2000. The immune system as a potential target for environmental estrogens (endocrine disrupters): A new emerging field. Toxicology 150:191-206.

Akaike H. 1974. A new look at the statistical model identification.

IEEE Trans Autom Control 19:716-723.

Battaglin WA, Kolpin DW, Scribner EA, Kuivila KM, Sandstrom MW. 2005. Glyphosate, other herbicides, and transformation products in 
midwestern streams, 2002: Agricultural hydrology and water quality. J Am Water Res Assoc 41:323-

332.

Bergman R. 1963. The anatomy of Ablabes baliodeira, a colubrid snake from Java. J Ohio Herpetol Soc 4:1-14.

Bigsby R, Chapin RE, Daston GP, Davis BJ, Gorski J, Gray LE, Howdeshell KL, Zoeller RT, vom Saal FS. 1999. Evaluating the effects of endocrine disruptors on endocrine function during development. Environ Health Perspect 107:613-618.

Brodkin MA, Madhoun H, Rameswaran M, Vatnick I. 2007. Atrazine is an immune disruptor in adult Northern Leopard Frogs (Rana pipiens). Environ Toxicol Chem 26:8084.

Campbell PM, Pottinger TG, Sumpter JP. 1994. Preliminary evidence that chronic confinement stress reduces the quality of gametes produced by brown and rainbow trout. Aquaculture 120:151-169.

Campero M, Ollevier F, Stoks R. 2007. Ecological relevance and sensitivity depending on the exposure time for two biomarkers. Environ Toxicol 22:572-581.

Coddington EJ, Cree A. 1995. Effect of acute captivity stress on plasma concentrations of corticosterone and sex steroids in female Whistling Frogs, Litoria ewingi. Gen Comp Endocrinol 100:33-38.

Colborn T, Thayer K. 2000. Aquatic ecosystems: Harbingers of endocrine disruption. Ecol Appl 10:949-957.

Cooper RL, Stoker TE, Tyrey L, Goldman JM, McElroy WK. 2000. Atrazine disrupts the hypothalamic control of pituitaryovarian function. Toxicol Sci 53:297-307.

Crews D, Willingham E, Skipper J. 2000. Endocrine disruptors: Present issues, future directions. Q Rev Biol 75:243-260.

Crisp TM, Clegg ED, Cooper RL, Wood WP, Anderson DG, Baetcke KP, Hoffmann JL, Morrow MS, Rodier DJ, Schaeffer JE. 1998. Environmental endocrine disruption: An effects assessment and analysis. Environ Health Perspect 106:11.

Daston GP, Cook JC, Kavlock RJ. 2003. Uncertainties for endocrine disrupters: Our view on progress. Toxicol Sci 74:245-252.

de Solla SR, Martin PA. 2011. Absorption of current use pesticides by Snapping Turtle (Chelydra serpentina) eggs in treated soil. Chemosphere 85:820-825.

de Solla SR, Bishop C, Brooks R. 2002. Sexually dimorphic morphology of hatching 
Snapping Turtles (Chelydra serpentina) from contaminated and reference sites in the Great Lakes and St. Lawrence River Basic, North America. Environ Toxicol Chem 21:7.

de Solla SR, Martin P, Fernie K, Park B, Mayne G. 2006. Effects of environmentally relevant concentrations of atrazine on gonadal development of Snapping Turtles (Chelydra serpentina). Environ Toxicol Chem 25:520-526.

de Solla SR, Fernie KJ, Letcher RJ, Chu SG, Drouillard KG, Shahmiri S. 2007. Snapping Turtles (Chelydra serpentina) as bioindicators in Canadian areas of concern in the Great Lakes Basin. 1. Polybrominated diphenyl ethers, polychlorinated biphenyls, and organochlorine pesticides in eggs. Environ Sci Technol 41:7252-7259.

Dhabhar FS. 2009. Enhancing versus suppressive effects of stress on immune function: Implications for immunoprotection and immunopathology. Neuroimmunomodulation 16:300-317.

Edginton A, Rouleau C. 2005. Toxicokinetics of 14C-atrazine and its metabolites in stage-66 Xenopus laevis. Environ Sci Technol 39:8083-8089.

Elsey RM, Lance VA, Joanen T, McNease L. 1991. Acute stress suppresses plasma estradiol levels in female alligators (Alligator mississippiensis). Comp Biochem Physiol Part A: Physiol 100:649-651.

Fagin D. 2012. Toxicology: The learning curve. Nature 490:462465.

Fitch HS. 1987. Collecting and life-history techniques. In: Seigel RA, Collins JT, Novak SS, editors. Snakes: Ecology and Evolutionary Biology. New York: McGraw-Hill. p19.

Ford N. 1995. Experimental design in studies of snake behavior. Herpetol Monogr 9:130-139.

Forson D, Storfer A. 2006. Atrazine increases Ranavirus susceptibility in the Tiger Salamander, Ambystoma tigrinum. Ecol Appl 16:2325-2332.

French SS, Matt KS, Moore MC. 2006. The effects of stress on wound healing in male tree lizards (Urosaurus ornatus). Gen Comp Endocrinol 145:128-132.

French SS, DeNardo DF, Moore MC. 2007. Trade-offs between the reproductive and immune systems: Facultative responses to resources or obligate responses to reproduction? Am Nat 170:79-89.

Friedmann AS. 2002. Atrazine inhibition of testosterone production in rat males following peripubertal exposure. Reprod Toxicol 16:275-279.

Gibbons JW, Dorcas ME. 2004. North American Watersnakes: A Natural History. 
Norman: University of Oklahoma Press.496 p.

Gorge G, Nagel R. 1990. Kinetics and metabolism of 14C-lindane and 14C-atrazine in early life stages of zebrafish (Brachydanio rerio). Chemosphere 21:1125-1137.

Graham JH, Emlen JM, Freeman DC. 1993. Developmental stability and its applications in ecotoxicology. Ecotoxicology 2:175-184.

Gross LM. 2009. Long-Term Assessment of Predatory Fish Removal on a Pond-Breeding Amphibian Community in Central Illinois. Charleston: Eastern Illinois University.

Guillette L, Gunderson M. 2001. Alteration in development of reproductive and endocrine systems of wildlife populations exposed to endocrine-disrupting contaminants. Reproduction 122:857-864.

Gunderson MP, Kools SAE, Milnes MR, Guillette LJ. 2003. Effect of acute stress on plasma b-corticosterone, estradiol-17b and testosterone concentrations in juvenile American Alligators collected from three sites within the Kissimmee-Everglades drainage basin in Florida (USA). Comp Biochem Physiol Part C: Toxicol Pharmacol 135:365-374.

Hayes TB. 2004. There is no denying this: Defusing the confusion about atrazine. BioScience 54:1138-1149.

Hayes TB, Collins A, Lee M, Mendoza M, Noriega N, Stuart AA, Vonk A. 2002. Hermaphroditic, demasculinized frogs after exposure to the herbicide atrazine at low ecologically relevant doses. Proc Natl Acad Sci 99:5476-5480.

Hayes TB, Khoury V, Narayan A, Nazir M, Park A, Brown T, Adame L, Chan E, Buchholz D, Stueve T, Gallipeau S. 2010. Atrazine induces complete feminization and chemical castration in male African clawed frogs (Xenopus laevis). Proc Natl Acad Sci USA 107:4612-4617.

Hayes TB, Anderson LL, Beasley VR, de Solla SR, Iguchi T, Ingraham H, Kestemont P, Kniewald J, Kniewald Z, Langlois VS, Luque EH, McCoy KA, Muño-de-Toro M, Oka T, Oliveira CA, Orton F, Ruby S, Suzawa M, Tavera-Mendoza LE, Trudeau VL, VictorCosta AB, Willingham E. 2011. Demasculinization and feminization of male gonads by atrazine: Consistent effects across vertebrate classes. J Steroid Biochem Mol Biol 127:64-73.

Holem RR, Hopkins WA, Talent LG. 2008. Effects of repeated exposure to malathion on growth, food consumption, and locomotor performance of the Western Fence Lizard (Sceloporus occidentalis). Environ Pollut 152:92-98.

Hopkins W. 2000. Reptile toxicology: Challenges and opportunities on the last frontier in vertebrate ecotoxicology. Environ Toxicol Chem 19:2391-2393. 
Hopkins W, Mendonc, a M, Congdon J. 1997. Increased circulating levels of testosterone and corticosterone in Southern Toads, Bufo terrestris, exposed to coal combustion waste. Gen Comp Endocrinol 108:237-246.

Hopkins W, Rowe C, Congdon J. 1999. Elevated trace element concentrations and standard metabolic rate in Banded Watersnakes (Nerodia fasciata) exposed to coal combustion wastes. Environ Toxicol Chem 18:1258-1263.

King RB. 1993. Microgeographic, historical, and size-correlated variation in Water Snake diet composition. J Herpetol 27:90-94.

Langerveld AJ, Celestine R, Zaya R, Mihalko D, Ide CF. 2009. Chronic exposure to high levels of atrazine alters expression of genes that regulate immune and growth-related functions in developing Xenopus laevis tadpoles. Environ Res 109:379-389.

Langlois VS, Carew AC, Pauli BD, Wade MG, Cooke GM, Trudeau VL. 2009. Low levels of the herbicide atrazine alter sex ratios and reduce metamorphic success in Rana pipiens tadpoles raised in outdoor mesocosms. Environ Health Perspect 118:552-557.

Leary RF, Allendorf FW. 1989. Fluctuating asymmetry as an indicator of stress: Implications for conservation biology. Trends Ecol Evol 4:214-217.

Lorenzen A, Moon TW, Kennedy SW, Fox GA. 1999. Relationships between environmental organochlorine contaminant residues, plasma corticosterone concentrations, and intermediary metabolic enzyme activities in Great Lakes Herring Gull embryos. Environ Health Perspect 107:179-186.

Maina JN, Veltcamp CJ, Henry J. 1999. Study of the spatial organization of the gas exchange components of a snake lung - The sandboa Eryx colubrinus (Reptilia: Ophidia: Colubridae)—by latex casting. J Zool 247:81-90.

Matsushita S, Yamashita J, Iwasawa T, Tomita T, Ikeda M. 2006. Effects of in ovo exposure to imazalil and atrazine on sexual differentiation in chick gonads. Poult Sci $85: 1641-1647$.

McFarland CA, Quinn MJ Jr, Bazar MA, Remick AK, Talent LG, Johnson MS. 2008. Toxicity of oral exposure to 2, 4, 6 trinitrotoluene in the Western Fence Lizard (Sceloporus occidentalis). Environ Toxicol Chem 27:1102-1111.

Morgan KN, Tromborg CT. 2007. Sources of stress in captivity. Appl Anim Behav Sci 102:262-302.

Mullin SJ, Mushinsky HR. 1997. Use of experimental enclosures to examine foraging success in water snakes: A case study. J Herpetol 31:565-569. 
Murray SM, Gaines KF, Novak JM, Gochfeld M, Burger J. 2010. DNA double-strand breakage as an endpoint to examine metal and radionuclide exposure effects to water snakes on a nuclear industrial site. Hum Ecol Risk Assess 16:282-300.

Neuman-Lee L, Janzen FJ. 2011. Environmentally relevant levels of atrazine exposure at the onset of embryonic development impacts post-hatching behavior and survivorship of neonatal turtles. Herpetologica 67:23-31.

Newman AEM, Chin EH, Schmidt KL, Bond L, Wynne-Edwards KE, Soma KK. 2008. Analysis of steroids in songbird plasma and brain by coupling solid phase extraction to radioimmunoassay. Gen Comp Endocrinol 155:503-510.

Ohlendorf H, Hothem R, Aldrich T. 1988. Bioaccumulation of Selenium by snakes and frogs in the San Joaquin Valley, California. Copeia 1988:704-710.

Ottinger MA, Lavoie E, Thompson N, Barton A, Whitehouse K, Barton M, Abdelnabi M, Quinn M Jr, Panzica G, Viglietti-Panzica C. 2008. Neuroendocrine and behavioral effects of embryonic exposure to endocrine disrupting chemicals in birds. Brain Res Rev $57: 376-385$.

Palmer AR, Strobeck C. 1986. Fluctuating asymmetry: Measurement, analysis, patterns. Annu Rev Ecol Syst 17:391-421.

Palmer AR, Strobeck C. 1992. Fluctuating asymmetry as a measure of developmental stability: Implications of non-normal distributions and power of statistical tests. Acta Zool Fennica 191:57-72.

Parsons PA. 1992. Fluctuating asymmetry: A biological monitor of environmental and genomic stress. Heredity 68:361-364.

Pinson SE, Parr CM, Wilson JL, Navara KJ. 2011. Acute corticosterone administration during meiotic segregation stimulates females to produce more male offspring. Physiol Biochem Zool 84:292-298.

Pruett SB, Fan R, Zheng Q, Myers LP, Hebert P. 2003. Modeling and predicting immunological effects of chemical stressors:

Characterization of a quantitative biomarker for immunological changes caused by atrazine and ethanol. Toxicol Sci 75:343-354.

Qualls CP, Andrews RM. 1999. Cold climates and the evolution of viviparity in reptiles: Cold incubation temperatures produce poor-quality offspring in the lizard, Sceloporus virgatus. Biol J Linn Soc 67:353-376.

Riches R. 1976. Breeding snakes in captivity. St. Petersburg: Palmetto Publishing Company.90 p. 
Robert KA, Vleck C, Bronikowski AM. 2009. The effects of maternal corticosterone levels on offspring behavior in fast- and slow-growth garter snakes (Thamnophis elegans). Horm Behav 55:24-32.

Rohr JR, McCoy KA. 2010. A qualitative meta-analysis reveals consistent effects of atrazine on freshwater fish and amphibians. Environ Health Perspect 118:20-32.

Romero LM, Reed JM. 2005. Collecting baseline corticosterone samples in the field: Is under 3 min good enough? Comp Biochem Physiol Part A: Mol Integr Physiol 140:7379.

Romero LM, Wikelski M. 2001. Corticosterone levels predict survival probabilities of Galapagos marine iguanas during El Nino events. Proc Natl Acad Sci USA 98:73667370 .

Rooney AA, Matulka RA, Luebke RW. 2003. Developmental atrazine exposure suppresses immune function in male, but not female Sprague-Dawley Rats. Toxicol Sci 76:366-375.

Ross P, De Swart R, Addison R, Van Loveren H, Vos J, Osterhaus A. 1996. Contaminant-induced immunotoxicity in harbour seals: Wildlife at risk? Toxicology 112:157-169.

Shine R, Olsson MM, LeMaster MP, Moore IT, Mason RT. 2000. Are snakes righthanded? Asymmetry in hemipenis size and usage in gartersnakes (Thamnophis sirtalis). Behav Ecol 11:411-415.

Solomon KR, Baker DB, Richards RP, Dixon KR, Klaine SJ, La Point TW, Kendall RJ, Weisskopf CP, Giddings JM, Giesy JP, Hall LW Jr, Williams WM. 1996. Ecological risk assessment of atrazine in North American surface waters. Environ Toxicol Chem 15:3176.

Solomon KR, Carr JA, Du Preez LH, Giesy JP, Kendall RJ, Smith EE, Van Der Kraak GJ. 2008. Effects of atrazine on fish, amphibians, and aquatic reptiles: A critical review. Crit Rev Toxicol 38:721-772.

Storrs S, Kiesecker J. 2004. Survivorship patterns of larval amphibians exposed to low concentrations of atrazine. Environ Health Perspect 112:1054-1057.

Talent L, Dumont J, Bantle J, Janz D, Talent S. 2002. Evaluation of Western Fence Lizards (Sceloporus occidentalis) and Eastern Fence Lizards (Sceloporus undulatus) as laboratory reptile models for toxicological investigations. Environ Toxicol Chem 21:899905.

Taylor E, DeNardo D, Jennings D. 2004. Seasonal steroid hormone levels and their relation to reproduction in the Western Diamond-backed Rattlesnake, Crotalus atrox 
(Serpentes: Viperidae). Gen Comp Endocrinol 136:328-337.

Vos JG, Moore JA. 1977. Immune suppression as related to toxicology.

Crit Rev Toxicol 5:67-101.

Weatherhead PJ, Brown GP, Prosser MR, Kissner KJ. 1998. Variation in offspring sex ratios in the Northern Watersnake (Nerodia sipedon). J Zool 76:2200-2206.

Weir SM, Suski JG, Salice CJ. 2010. Ecological risk of anthropogenic pollutants to reptiles: Evaluating assumptions of sensitivity and exposure. Environ Pollut 158:35963606.

Whittier J, Mason R, Crews D. 1987. Plasma steroid hormone levels of female red-sided garter snakes, Thamnophis sirtalis parietalis:

Relationship to mating and gestation. Gen Comp Endocrinol 67:33-43.

Willingham E. 2005. The effects of atrazine and temperature on turtle hatchling size and sex ratios. Front Ecol Environ 3:309-313.

Winne CT, Willson JD, Andrews KM, Reed RN. 2006. Efficacy of marking snakes with disposable medical cautery units. Herpetol Rev 37:52-54. 